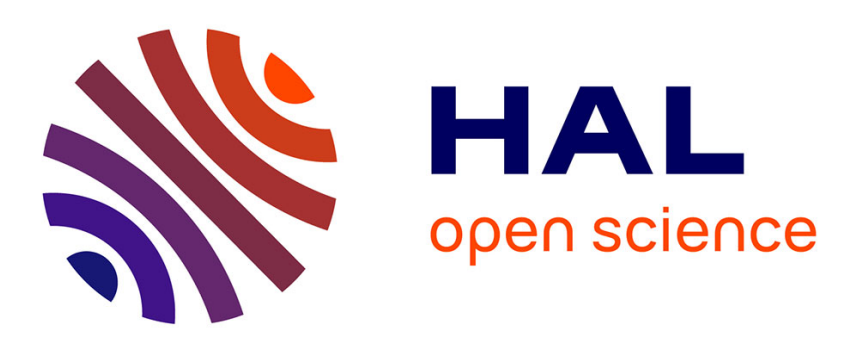

\title{
Lanthanide borohydrido complexes for MMA polymerization: syndio- vs iso- stereocontrol
}

Denise Barbier-Baudry, Frédéric Bouyer, Ana Sofia Madureira Bruno, Marc

Visseaux

\section{- To cite this version:}

Denise Barbier-Baudry, Frédéric Bouyer, Ana Sofia Madureira Bruno, Marc Visseaux. Lanthanide borohydrido complexes for MMA polymerization: syndio- vs iso- stereocontrol. Applied Organometallic Chemistry, 2006, 20, pp.24-31. 10.1002/aoc.1002 . hal-00105931

\section{HAL Id: hal-00105931 \\ https://hal.science/hal-00105931}

Submitted on 13 Oct 2006

HAL is a multi-disciplinary open access archive for the deposit and dissemination of scientific research documents, whether they are published or not. The documents may come from teaching and research institutions in France or abroad, or from public or private research centers.
L'archive ouverte pluridisciplinaire HAL, est destinée au dépôt et à la diffusion de documents scientifiques de niveau recherche, publiés ou non, émanant des établissements d'enseignement et de recherche français ou étrangers, des laboratoires publics ou privés. 


\section{Lanthanide Borohydrido Complexes for MMA}

\section{Polymerisation : Syndio- versus Iso- Stereocontrol}

Denise Barbier-Baudry ${ }^{a}$, Frédéric Bouyer ${ }^{a}$, Ana Sofia Madureira Bruno ${ }^{a}$ and $\operatorname{Marc~Visseaux~}^{\mathrm{a}, \mathrm{b}, *}$

${ }^{a}$ Laboratoire de Synthèse et d'Electrosynthèse Organométalliques, UMR 5188-CNRS, Faculté des Sciences "Mirande", 9, av. Alain Savary, 21078 Dijon Cédex, France.

${ }^{\mathrm{b}}$ Laboratoire de Catalyse de Lille, Groupe Catalyse Homogène, UMR 8010-CNRS, ENSCL, 59655 Villeneuve d'Ascq Cédex, France.

fax (+33) 320436585, e-mail : Marc.Visseaux@ensc-lille.fr 


\section{Abstract}

This paper presents an extensive study of the polymerisation of MMA with borohydrido lanthanide complexes for the first time. Catalytic systems are made of a lanthanide derivative bearing zero, one, or two bulky ligands: substituted cyclopentadienyl $\left(\mathrm{Cp}^{*}{ }^{\prime}=\right.$ $\left.\mathrm{C}_{5} \mathrm{Me}_{4} n \mathrm{Pr}, \mathrm{Cp}^{4 \mathrm{i}}=\mathrm{C}_{5} \mathrm{HiPr}_{4}, \mathrm{Cp}^{\mathrm{Ph} 3}=\mathrm{H}_{2} \mathrm{C}_{5} \mathrm{Ph}_{3}-1,2,4\right)$, and/or diketiminate $([(p$-tol $) \mathrm{NN}]=$ $\left.\left[\left(p-\mathrm{CH}_{3} \mathrm{C}_{6} \mathrm{H}_{4}\right) \mathrm{N}\left(\mathrm{CH}_{3}\right) \mathrm{C}\right]_{2} \mathrm{CH}\right)$, in the presence of variable quantities of alkylating agent. With BuLi in apolar medium, highly isotactic polymer (up to $95.6 \%$ ) is formed. In THF, syndiotactic-rich PMMA is obtained whatever the nature of the co-catalyst (BuLi or $\mathrm{Mg}^{\mathrm{n}} \mathrm{Bu}_{2}$ ). The presence of an electron-withdrawing ligand such as $\mathrm{Cp}^{\mathrm{Ph} 3}$ allows high syndio-regularity, up to $81.8 \%$ at $0{ }^{\circ} \mathrm{C}$, together with the highest conversion. There is quite good concordance between calculated and experimental molecular data in THF. Divalent $\mathrm{Cp}^{*}{ }_{2} \mathrm{Sm}^{\mathrm{II}}(\mathrm{THF})$ and $\left(\mathrm{Cp}^{\mathrm{Ph} 3}\right)_{2} \mathrm{Sm}^{\mathrm{II}}(\mathrm{THF})$ are active as single-component initiators, the former affords PMMA $88 \%$ syndiotactic at $0{ }^{\circ} \mathrm{C}$.

Keywords : lanthanides, borohydride, MMA polymerisation, PMMA, tacticity 


\section{Introduction}

During the last two decades the use of organolanthanide complexes for catalysis developped extensively, ${ }^{1}$ and specially in favour of polymerisation. ${ }^{2,}{ }^{3}$ Among these complexes, hydrides and alkyls were the most preferred. However, if the lanthanide hydrides have been proved to be powerful catalysts towards a lot of interesting chemical transformations, their access remains a challenging problem, since they are exceedingly reactive. ${ }^{4}$ Also, they are obtained by hydrogenolysis of alkyl derivatives, which require drastic protection towards air or moisture. ${ }^{5}$ Since more recently, some new tendencies appeared like the search of alternatives to the ubiquitous [Ln]-H or [Ln]-R functions, i.e. the in situ alkylation of a pre-catalyst, ${ }^{6}$ or the use of borane-supported hydrides [Ln]$\mathrm{HBR}_{3},{ }^{7}$ or borohydrides [Ln]-BH${ }_{4}{ }^{8}$ In sharp contrast with [Ln]-H compounds, complexes bearing a $[\mathrm{Ln}]-\mathrm{BH}_{4}$ function are easily obtained and very stable. Lanthanide borohydrides were just described as active towards $\varepsilon$-caprolactone polymerization, showing a behaviour very similar to that of a pure lanthanide hydride. ${ }^{9}$ On the other hand, towards apolar monomers, such compounds display a typical halide behaviour: the presence of a $\mathrm{MgR}_{2}$ co-catalyst was necessary to enable isoprene ${ }^{10}$ or ethylene $^{11}$ polymerisation.

The controlled polymerisation of methyl methacrylate had been largely explored in the 1990 's, ${ }^{12,13}$ and particularly with lanthanide initiators. ${ }^{14-18}$ Among the reasons for this interest is the search of processes affording high-valuated material, like syndiotactic PMMA. ${ }^{19-21}$ Lanthanide complexes ${ }^{3,14,16,19,22-24}$ were found particularly efficient for this purpose, with syndiotacticity exceeding $95 \%$ but obtained at very low $\left(-95^{\circ} \mathrm{C}\right)$ temperature. The high syndioregularity seemed correlated to the use of ancillary bulky ligands, diketiminate or peralkylated $\mathrm{Cp}$ groups, but earlier studies also showed the 
importance of the solvent, ${ }^{25-27}$ and the presence of a co-catalyst. ${ }^{28}$ Anionic polymerisation of MMA initiated by cuprate reagent resulted in highly syndiotactic materials when the experiments were conducted in polar solvent, ${ }^{29}$ and predominantly isotactic in toluene. ${ }^{30}$

In the course of our studies concerning the valorisation of lanthanide borohydrides for polymerisation, ${ }^{10,11,31}$ we purposed to investigate the potential of such versatile compounds as initiators vs. MMA. Experiments were carried out with different borohydrido complexes bearing 1,2 , or $3 \mathrm{BH}_{4}$ functions. The results are presented and discussed in the following paper in terms of nature of the metal ( $\mathrm{Sm}$ or $\mathrm{Nd}$ ), electron donation ability and bulkiness of the ancillary ligands. The role of the polarity of the solvent, and the presence of different alkylating reagents as co-catalysts were also investigated.

\section{Results and discussion}

Preliminary experiments were preliminarily conducted by using $\mathrm{Cp}^{4 \mathrm{i}}{ }_{2} \mathrm{Sm}\left(\mathrm{BH}_{4}\right)$ (4), in the absence of co-catalyst. With a MMA/4 ratio of 50, quantitative consumption of the monomer was obtained within 4 hours at room temperature. The polydispersity was acceptable, 1.45 , but $\bar{M}_{n}$ value was found to be much higher than expected (ca. 100 times higher), denoting that only a small percentage of the catalyst had initiated the reaction. However, these preliminary results were considered motivating since a significant control of the tacticity ( $\mathrm{rr} 76 \%$ ) was observed, in sharp contrast with the conventional, aspecific, radical polymerisation of MMA. 
The formation of such a high molecular weight polymer was tentatively attributed to the mechanism of the initiation reaction. Indeed, a borohydride group can react with a conjugated carbonyl function, following 1,2- or 1,4- addition. As shown by Yasuda and coll., only the latter pathway leads to an enolate, active in MMA polymerisation, ${ }^{14}$ whereas upon 1,2- addition, the resulting alkoxy group is inactive towards the monomer. It is well-known that hard hydrides or Grignard reagents lead preferentially to 1,2- addition, whereas soft reagents such as cuprates give rise to a major ratio of 1,4addition. ${ }^{32}$ Whereas a reagent made of a group III metal remains essentially hard in nature, the controlled polymerisation of MMA could however be obtained from lanthanide alkyl organometallic derivatives. ${ }^{33}$ In order to induce a softer character, we attempted to change the hard (boro)hydride ligand for a softer carbon derivative. A series of neodymium and samarium borohydrides complexes were used in this frame. Borohydrides groups were substituted by zero (S0), one (S1) or two (S2) sterically demanding groups (Chart 1), and we studied the ability of such complexes, as precatalysts, in the presence of variable quantities of alkylating reagent.

((Chart 1))

\subsection{S0 systems}

Table 1 summarises the results of MMA polymerisation obtained with $\mathrm{Nd}\left(\mathrm{BH}_{4}\right)_{3}(\mathrm{THF})_{3}$ (1a) and 3 equivalents of $\mathrm{Mg}^{\mathrm{n}} \mathrm{Bu}_{2}$ or 4 equivalents of BuLi. The choice of this stoichiometry results from a previous study devoted to the use of $\mathbf{1 a}$ as an initiator for conjugated dienes polymerisation. ${ }^{31}$ Blank experiments performed with BuLi at $0{ }^{\circ} \mathrm{C}$ in 
toluene and THF, afforded isotactic-rich or syndiotactic-rich polymer respectively, but in very low yields (runs 5,8 ). The polymerisation of MMA was first performed at -40 ${ }^{\circ} \mathrm{C}$, in polar, THF, or non polar solvent, toluene or hexane. In standard conditions, yields up to $80 \%$ (runs 3,4 and 6,7) were observed. From Table 1, the nature of the solvent has a decisive influence on the course of the reaction, as also emphasized in a recent study: ${ }^{34}$ in THF, whatever the reagent, lithium or magnesium alkyl, a highly syndiotactic material is formed. On the opposite, if the reaction is performed in toluene, the choice of the alkylating reagent has a great influence. In the presence of $\mathrm{Mg}^{\mathrm{n}} \mathrm{Bu}_{2}$, no stereocontrol is observed (run 2), whereas the use of BuLi leads to a highly isotactic PMMA (run 4). A good stereocontrol could be obtained at $0{ }^{\circ} \mathrm{C}$, by adding an aluminum phenoxide (run 3), known as an activator for MMA polymerisation. ${ }^{22,} 35$ This additive has a drastic effect in the absence of alkyl co-catalyst, allowing the formation of highly syndiotactic PMMA (run 1). With BuLi as an alkylating agent, activity is also noticeably increased in the presence of the aluminium additive (95\% in $3 \mathrm{~h}$ for run 3 ; to be compared to $92 \%$ in $23 \mathrm{~h}$ for run 4 ), whereas the tacticity is unchanged.

\section{$(($ Table 1))}

Most of these results are interesting in terms of stereocontrol, but they are less satisfactory concerning the molecular weights concordance, between measured $\bar{M}_{n \text { (meas.) }}$ and calculated $\bar{M}_{n}($ calc.) obtained according to the following relationship:

$$
\bar{M}_{n}(\text { calc. })=\{([\text { monomer }] /[\mathrm{Nd}]) \cdot \text { yield }\} /[\text { cocatalyst }]
$$


In most cases, SEC analysis indicated too high molecular weights (110000 measured for 10000 expected, run 7, for example). In the presence of an $\mathrm{Al}$ activator, the control of macromolecular data is improved, with narrower PDI (ca. 1.8, runs 1-3).

\subsection{S1 Systems}

Monocyclopentadienyl complexes of the early lanthanides are known to be stable with respect to disproportionation in case of bulky Cp groups only. ${ }^{36,}{ }^{37} \mathrm{We}$ used as sterically demanding ligands substituted $\mathrm{Cp}$ groups : $\mathrm{Cp}^{*}$, and $\mathrm{Cp}^{\mathrm{Ph} 3}$, the latter being very bulky but less donor than a peralkylated one (Chart 1). Experiments were conducted at $0{ }^{\circ} \mathrm{C}$, results are summarized in Table 2 . In THF, the $\mathbf{2 a} / \mathrm{BuLi}$ system allowed a syndio control ( $\operatorname{rr} 72.7 \%$, run 9) which is close to that obtained at $-40{ }^{\circ} \mathrm{C}$ ( $\operatorname{rr} 75.5 \%$, run 7 , Table 1). One may observe that if activities are in general sensibly lower for halflanthanidocenes in comparison with $1 \mathbf{a}$ (Table 1), the stereocontrol is preserved at $0{ }^{\circ} \mathrm{C}$. In toluene, an excellent iso-control was observed (mm $93.6 \%$, run 10) but yields were lower and molecular weights remained much higher than expected. On that subject, one can remember that the monoCp complex $\mathrm{Cp}^{*}{ }^{\prime} \mathrm{Sm}\left(\mathrm{BH}_{4}\right)_{2}$ is not monomeric: ${ }^{36}$ it was identified as an associated form, hexanuclear clusters. It is probable that in toluene, even in the presence of the polar monomer, and after the addition of an alkylating reagent, the precursor remained under an associated form, giving rise to an initiating species that is clearly not a well defined monomolecular one. On the other way, in THF, the bridges formed by $\mathrm{R}$ or $\mathrm{BH}_{4}$ groups are usually broken and definite monomeric species are formed. No stereospecificity was observed with $\mathbf{2 b}$ and $\mathrm{Mg}^{\mathrm{n}} \mathrm{Bu}_{2}$ (stoichiometric amount 
or excess, runs 11,12 ) as co-catalyst, whereas the presence of $\mathrm{Cp}^{\mathrm{Ph} 3}$ ligand seems to induce some syndio-control (run 14).

((Table 2))

\subsection{S2 systems}

To be sure that in non polar solvent the initiators would be under a non associated form, the use of disubstituted borohydrides seemed opportune: even in non coordinating solvents, these electron rich complexes of formula $\mathrm{L}_{2} \mathrm{Ln}\left(\mathrm{BH}_{4}\right)$ remain generally monomeric, eventually dimeric, but these dimers are easily cleaved by polar molecules. Ligands were chosen among $\mathrm{Cp}$ groups, as same as for the $\mathrm{S} 1$ systems, but in order to vary the electronic density around the metal, another bulky ligand, the diketiminate [ $p$ $\left.\left.\mathrm{CH}_{3} \mathrm{C}_{6} \mathrm{H}_{4}\right) \mathrm{N}\left(\mathrm{CH}_{3}\right) \mathrm{C}\right]_{2} \mathrm{CH}$, referred to as $[(p$-tol $) \mathrm{NN}]$, was used. This coordinate was in some cases considered as a six electron ligand like a cyclopentadienyl, but it is essentially dihapto, bonded by the nitrogen atoms and is considered as less donor than a Cp group. ${ }^{38}$ The difference in the access to the metal governed by the different ligands might induce different stereochemistry for the polymerisation reaction. Metallocene 4 and heteroleptic pre-catalysts $7 \mathbf{a}, 7 \mathbf{b}$ were available in the laboratory, complexes $\mathbf{6}$ and $\mathbf{8}$ were prepared as described (see experimental). In some cases, pre-catalysts were prepared directly in situ, by addition of the required amount of anionic ligand to a trisborohydride or a bisborohydride precursor, followed by the convenient pre-reaction time. They are noted as $\mathbf{4}^{\prime}\left(\mathbf{1 b}+2 \mathrm{KCp}^{4 \mathrm{i}}\right), \mathbf{5}^{\prime}\left(\mathbf{2 a}+\mathrm{KCp}^{*}\right), \mathbf{6}^{\prime}\left(\mathbf{3}+\mathrm{KCp}^{\mathrm{Ph} 3}\right)$. Selected results are gathered in table 3 . 
((Table 3))

One can first notice that the presence of a co-catalyst is not absolutely necessary: in a preliminary experiment (run 15), complete conversion could be obtained with 4 alone (but for a [monomer]/[catalyst] ratio equal to 50). As shown by runs 16 and 17, performed in similar conditions, 4' gives rise to results which compare well with those obtained with genuine 4 . In addition, we checked that $\mathrm{KBH}_{4}$, by-product formed in such in situ preparations, was indifferent with respect to MMA polymerisation. The use of complexes prepared in situ is thus established as legitimate. A high iso-control is obtained with BuLi as alkylating agent (run 16).

With 5', SEC data point out a more satisfactorily controlled process, experimental molecular weights are close to the theoretical ones (runs 19, 20, 21). The yield is quantitative when the experiment is performed in toluene and in the presence of $\mathrm{Mg}^{\mathrm{n}} \mathrm{Bu}_{2}$ (run 22). The previous tendency is then observed again: highly syndio-regular polymer is obtained in THF when using $\mathrm{Mg}^{\mathrm{n}} \mathrm{Bu}_{2}$ as a co-catalyst, (rr $78 \%$, run 20), whereas isotactic PMMA is formed with BuLi in toluene ( $\mathrm{mm} 77 \%$, run 21). The complex $\left(\mathrm{Cp}^{\mathrm{Ph} 3}\right)_{2} \mathrm{SmBH}_{4} \quad\left(6^{\prime}\right)$, bearing two bulky cyclopentadienyl ligands, in absence of alkylating reagent, affords in apolar medium highly syndiotactic material ( $\mathrm{rr} 81.8 \%$, run 23) (a blank test conducted with $\mathrm{KCp}^{\mathrm{Ph} 3} / \mathrm{Mg}^{\mathrm{n}} \mathrm{Bu}_{2}$ yielded atactic PMMA). The syndio percentage is lower with additives but the molecular weights can be controlled (run 24). With complexes bearing a diketiminate ligand, the monomer conversion is only significant in the presence of a co-catalyst. With $\mathrm{BuLi}$, both $\mathbf{7 a}$ and $\mathbf{7 b}$ afford isotactic polymer (runs 25,26$)$, up to $95.6 \%$. The low polydispersity $(\mathrm{PDI}=1.5)$ suggests that 
one unique active species might be formed, but only a fraction of the catalyst is likely involved in the process, giving consequently high molecular weight PMMA (run 25). In toluene, 8/BuLi catalyst affords isotactic PMMA (run 28), whereas in THF the system allows preferential and nearly quantitative formation of syndiotactic polymer (run 27). DSC analyses were performed for the most regular PMMAs, Tg were found at $132{ }^{\circ} \mathrm{C}$, $88{ }^{\circ} \mathrm{C}$, and $58{ }^{\circ} \mathrm{C}$, corresponding to runs 23 (81.8\% syndio), 18 (atactic), and 16 (92.3 $\%$ iso), respectively. As expected, the more the syndioregularity, the higher the $\mathrm{Tg}$ value. $^{39}$

As a matter of comparison, MMA polymerisation experiments were performed with divalent samarocenes 9, 10 and 11 (Chart 2). ${ }^{40}$ No co-catalyst was used, and the experiments were carried out in toluene at $0^{\circ} \mathrm{C}$. The polymerisation mechanism was explained in details by Novak et al. and involves the oxidation of $\mathrm{Sm}^{\mathrm{II}}$ in $\mathrm{Sm}^{\mathrm{III}}$ along with the formation of an enolate moiety. ${ }^{15}$ The results, summarised in table 4 , clearly show the influence of the ligands surrounding the samarium atom. With samarocene $\mathbf{9}$, both low conversion and wide polydispersity may be related to the poor affinity of the complex towards polar molecules, ${ }^{41}$ including MMA (run 29). The polymer was found $88 \%$ syndiotactic with the $\mathrm{Cp}^{*}$, ligand (initiator $\mathbf{1 0}$, run 30 ), one of the best results yet obtained at $0{ }^{\circ} \mathrm{C},{ }^{24}$ and $78 \%$ with $\mathrm{Cp}^{\mathrm{Ph} 3}$ (initiator 11, run 31). The behaviour of initiator $\mathbf{1 1}$ is very similar to this of 6' (table 3, run 23), which argues for the same enolate active species. SEC traces were monomodal with initiators $\mathbf{1 0}$ and $\mathbf{1 1}$, indicating that the initiation step occurs readily, leading to one unique active species. The formation of a high $\overline{D P}_{n}$ polymer with 11 may be related to the more difficult oxidation/initiation step.

((Chart 2)) 


\section{Concluding remarks}

As a summary,

- Borohydride complexes allow MMA polymerisation, the $\mathrm{BH}_{4}$ group behaves thus rather like a pseudohalide, than a pure hydride. In the absence of alkylating reagent, higher conversion may be obtained with $\mathrm{L}_{2} \mathrm{LnBH}_{4}$ complexes rather than with homoleptic $\operatorname{Ln}\left(\mathrm{BH}_{4}\right)_{3}$. This is in sharp contrast with the observed sluggishness of $\left(\mathrm{C}_{5} \mathrm{Me}_{5}\right)_{2} \mathrm{SmCl}(\mathrm{THF}){ }^{24}$

- In THF, there is a clear propensity for syndio-control, whatever the co-catalyst. A more significant syndioregularity is also observed, but in toluene, for two kinds of metallocenes both in the absence of co-catalyst: $\left(\mathrm{Cp}^{\mathrm{Ph} 3}\right)_{2} \mathrm{Sm}\left(\mathrm{BH}_{4}\right)$, and the divalent $\mathrm{Cp}{ }_{2}{ }_{2} \mathrm{Sm}$. The global unexpectedly high activity for $\mathrm{Cp}^{\mathrm{Ph} 3}$ complexes may be ascribable to the ease of coordination of the monomer to the acidic metal. Consequently, the hypothesis of a pseudo-ionic mechanism in toluene, leading to chain-end control polymerisation, can be advanced.

- In the presence of an aluminium phenoxide activator, $\mathrm{Nd}\left(\mathrm{BH}_{4}\right)_{3}(\mathrm{THF})_{3}$ affords PMMA more than $80 \%$ syndioregular.

- A very good iso-control (up to $95.6 \%$ ) is obtained with heteroleptic complexes 7a, $7 \mathbf{b}$ and 8 using BuLi in toluene, as also observed with half-lanthanidocenes and hindered complex 4 .

- About the control of macromolecular data, the $\mathrm{Ln}^{-\mathrm{BH}_{4}}$ moiety behaves like a $\mathrm{Ln}-\mathrm{NR}_{2}{ }^{42}$ or a $\mathrm{Ln}-\mathrm{CH}\left(\mathrm{SiMe}_{3}\right)_{2}$ one, ${ }^{16}$ providing faster propagation than initiation. 
Among the metallocenes, $\mathrm{Cp}^{*}$, trivalent complexes allow a well-controlled polymerisation.

\section{Experimental}

\subsection{Materials and methods}

All manipulations were carried out under argon atmosphere and using Jacomex glove box and standard Schlenk techniques. Toluene and THF (Aldrich) were dried and deoxygenated by storage over sodium/benzophenone ketyl before use. BuLi (1.6 M hexane) and $\mathrm{Mg}^{\mathrm{n}} \mathrm{Bu}_{2}$ (1.0 $\mathrm{M}$ heptane) (Aldrich) were used as received. (2,6- ${ }^{\mathrm{t}} \mathrm{Bu}-4-\mathrm{Me}-$ $\left.\mathrm{C}_{6} \mathrm{H}_{3} \mathrm{O}\right)_{2} \mathrm{AlEt}$ was prepared as described. ${ }^{22,}{ }^{35}$ MMA (Aldrich) was washed in $10 \% \mathrm{wt}$ $\mathrm{NaOH}$, then in deionized water until neutral $\mathrm{pH}$. The monomer was distilled and dried two times on $\mathrm{CaH}_{2}$, stored under argon over molecular sieves and redistilled before use. ${ }^{1} \mathrm{H}$ NMR spectra were recorded on a Bruker Avance 300 spectrometer at $300 \mathrm{~K}$. Chemicals shifts are expressed in parts per millions downfield from external TMS. Elemental analyses were performed with a Fisons EA 1108 CHON apparatus.

The syntheses of $\mathrm{KCp}^{\mathrm{Ph} 3}\left(\mathrm{Cp}^{\mathrm{Ph} 3}=\mathrm{H}_{2} \mathrm{C}_{5} \mathrm{Ph}_{3}-1,2,4\right),{ }^{43}[(p$-tol $) \mathrm{NN}] \mathrm{K}([(p$-tol $) \mathrm{NN}]=[(p$ $\left.\left.\mathrm{CH}_{3} \mathrm{C}_{6} \mathrm{H}_{4}\right) \mathrm{N}\left(\mathrm{CH}_{3}\right) \mathrm{C}\right]_{2} \mathrm{CH}^{44}$ and of the lanthanides complexes: $\mathrm{Ln}\left(\mathrm{BH}_{4}\right)_{3}(\mathrm{THF})_{3}(\mathrm{Ln}=\mathrm{Nd}$ (1a), $\operatorname{Sm}(\mathbf{1 b})),{ }^{45} \mathrm{Cp}^{*}{ }^{\prime} \operatorname{Ln}\left(\mathrm{BH}_{4}\right)_{2}(\mathrm{THF})_{2}(\operatorname{Ln}=\mathrm{Nd}(\mathbf{2 a}), \operatorname{Sm}(\mathbf{2 b}))\left(\mathrm{Cp}^{*}{ }^{\prime}=\mathrm{C}_{5} \mathrm{Me}_{4} n \operatorname{Pr}\right),{ }^{36}$ $\left.\mathrm{Cp}^{4 \mathrm{i}}{ }_{2} \mathrm{Sm}\left(\mathrm{BH}_{4}\right)(\mathbf{4})\left(\mathrm{Cp}^{4 \mathrm{i}}=\mathrm{C}_{5} \mathrm{HiPr}\right)_{4}\right),{ }^{46} \mathrm{Cp}^{*}{ }^{\prime} \operatorname{Ln}\{(p-$ tol $) \mathrm{NN}\}\left(\mathrm{BH}_{4}\right)(\mathrm{Ln}=\mathrm{Nd}(\mathbf{7 a}), \mathrm{Sm}$ (7b)), ${ }^{44} \mathrm{Cp}^{4 \mathrm{i}}{ }_{2} \mathrm{Sm}^{\mathrm{II}}(\mathbf{9})^{41} \mathrm{Cp}^{*}{ }_{2} \mathrm{Sm}^{\mathrm{II}}(\mathrm{THF})(\mathbf{1 0}),{ }^{40}$ and $\left(\mathrm{Cp}^{\mathrm{Ph} 3}\right)_{2} \mathrm{Sm}^{\mathrm{II}}(\mathrm{THF})(\mathbf{1 1})^{40}$ were described in the referenced papers. 


\subsection{Attempted synthesis of $\mathrm{Cp}^{\mathrm{Ph} 3} \mathrm{Sm}\left(\mathrm{BH}_{4}\right)_{2}(\mathrm{THF})_{2}(\mathbf{3})$}

The bulk synthesis was performed as described for $\mathbf{2 b}$. A flame dried vessel was charged in the glove box with $452 \mathrm{mg}(1.10 \mathrm{mmol})$ of $\mathrm{Sm}\left(\mathrm{BH}_{4}\right)_{3}(\mathrm{THF})_{3}(\mathbf{1 b})$ and 365 $\mathrm{mg}(1.10 \mathrm{mmol})$ of $\mathrm{KCp}^{\mathrm{Ph} 3}$. The vessel was connected to the vacuum line, toluene (40 $\mathrm{mL}$ ) was added by vacuum distillation. After 16 hours stirring at room temperature, the usual work up afforded $680 \mathrm{mg}$ of a red powder. ${ }^{1} \mathrm{H}$ NMR analysis showed the formation of two set of signals compatible with the formation of $\left(\mathrm{Cp}^{\mathrm{Ph} 3}\right) \mathrm{Sm}\left(\mathrm{BH}_{4}\right)_{2}(\mathrm{THF})_{2} \quad(3)$ (major product, $\left.85 \%\right)$ and $\left(\mathrm{Cp}^{\mathrm{Ph} 3}\right)_{2} \mathrm{Sm}\left(\mathrm{BH}_{4}\right)(\mathrm{THF}) \quad(6)$ (minor product, $15 \%$ ). By addition of the required quantity of $\mathrm{KCp}^{\mathrm{Ph} 3}$, the signals of 6 decreased significantly. It was observed that the addition of a very large excess of $\mathbf{1 b}$ was necessary to eliminate the signals of $\mathbf{6}$. Attempts to purify $\mathbf{3}$ by selective crystallisation failed: according to ${ }^{1} \mathrm{H}$ NMR, it was always contaminated by $10-15 \%$ of 6. ${ }^{1} \mathrm{H}$ NMR $\left(\mathrm{C}_{6} \mathrm{D}_{6}\right): 10.0$ (s, 2H, HCp), $7.85(\mathrm{dd}, 2 \mathrm{H}, o$ - $\mathrm{Ph}), 7.55$ (d, 4H, o-Ph), $7.02(\mathrm{~m}$, 3H, m'p'-Ph), 6.95 (t, 2H, p-Ph), 6.85 (t, 4H, m-Ph), 2.8 (16H, THF), 0.5 (16H, THF), $9.2\left(\mathrm{~m}, 8 \mathrm{H}, \mathrm{BH}_{4}\right)$. A second synthesis was performed by mixing $\mathbf{6}, 200 \mathrm{mg}(0.242$ mmol $)$ and $\mathbf{1 b}, 110 \mathrm{mg}(0.27 \mathrm{mmol})$ in $20 \mathrm{ml}$ of toluene. The solution was refluxed during 16 hours, then evaporated and extracted with pentane affording $210 \mathrm{mg}$ of crude material. As before, the isolated product contained nearly $20 \%$ of 6 (NMR control). Obviously the mono substituted complex $\mathbf{3}$ is in equilibrium with $\mathbf{1 b}$ and $\mathbf{6}$, as frequently observed for ligands of poor electron donating ability. ${ }^{47,48}$ Crude $\mathbf{3}$ was thus used just as it is for further polymerisation experiments.

\subsection{Direct Synthesis of $\left(\mathrm{Cp}^{\mathrm{Ph} 3}{ }_{2} \mathrm{Sm}\left(\mathrm{BH}_{4}\right)(\mathrm{THF})(\mathbf{6})\right.$}


A flame dried vessel was charged in the glove box with $151.8 \mathrm{mg}(0.36 \mathrm{mmol})$ of $\mathrm{Sm}\left(\mathrm{BH}_{4}\right)_{3}(\mathrm{THF})_{3}$ and $243.6 \mathrm{mg}(0.72 \mathrm{mmol})$ of $\mathrm{KCp}^{\mathrm{Ph} 3}$, then $5 \mathrm{~mL}$ of toluene were added by vacuum tranfer. The resulting solution was stirred for one night under argon atmosphere at room temperature. An orange solution was obtained. The solvent was evaporated and the precipitate was extracted twice with $10 \mathrm{~mL}$ of pentane. The solution was dried, giving a red powder $(\mathrm{m}=225 \mathrm{mg}, 75.6 \%)$. A sample of analytical purity was isolated as a toluene solvate, after two pentane-toluene extraction allowing the elimination of remaining salts. Anal. Calc. for $\mathrm{C}_{50} \mathrm{H}_{46} \mathrm{OSmB}, 0.5$ toluene: $\mathrm{C} 73.84 ; \mathrm{H}$ 5.79; Found C 74.17; H 5.55. ${ }^{1} \mathrm{H}$ NMR $\left(\mathrm{C}_{6} \mathrm{D}_{6}\right)$ was identical as observed for an NMR synthesis of $\mathbf{6}$ by adding in $\mathrm{C}_{6} \mathrm{D}_{6} 5.2 \mathrm{mg}\left(1.2610^{-5} \mathrm{~mol}\right)$ of $\mathbf{1 b}$ to $8.4 \mathrm{mg}\left(2.5310^{-5} \mathrm{~mol}\right)$ of $\mathrm{KCp}^{\mathrm{Ph} 3}: 12.7$ (s, 2H, HCp), 11.0 (s, 2H, HCp), 9.2 (br, 4H, o $o_{1} \mathrm{Ph}$ ), 7.2 (br, 6H, $m_{1}, p_{1^{-}}$ $\mathrm{Ph}), 7.0(\mathrm{~d}, 4 \mathrm{H}, o-\mathrm{Ph}), 6.7(\mathrm{t}, 2 \mathrm{H}, p-\mathrm{Ph}), 6.6(\mathrm{t}, 4 \mathrm{H}, m-\mathrm{Ph}), 6.4\left(\mathrm{t}, 2 \mathrm{H}, p_{2}-\mathrm{Ph}\right), 6.0(\mathrm{br}$, $\left.4 \mathrm{H}, m_{2}-\mathrm{Ph}\right), 5.0\left(\mathrm{br}, 4 \mathrm{H}, o_{2}-\mathrm{Ph}\right),-1.6(\mathrm{~d}, 8 \mathrm{H}, \mathrm{THF}),-16.3\left(\mathrm{~m}, 4 \mathrm{H}, \mathrm{BH}_{4}\right)$.

\subsection{Synthesis of $\left(\mathrm{Cp}^{\mathrm{Ph} 3}\right) \mathrm{Sm}\{(\mathrm{p}$-tol $) \mathrm{NN}\}\left(\mathrm{BH}_{4}\right) \mathbf{( 8 )}$}

A flame dried vessel was charged in the glove box with $410 \mathrm{mg}(0.1 \mathrm{mmol})$ of $\mathrm{Sm}\left(\mathrm{BH}_{4}\right)_{3}(\mathrm{THF})_{3}(\mathbf{1 b}), 332 \mathrm{mg}(0.1 \mathrm{mmol})$ of $\mathrm{KCp}^{\mathrm{Ph} 3}$, and $330 \mathrm{mg}(0.1 \mathrm{mmol})$ of $\{(p-$ tol)NN\}K then $50 \mathrm{~mL}$ of toluene were added by vacuum tranfer. A red solution was obtained after 22 hours of stirring. The solution was dried and the solid was extracted with pentane. After slow evaporation, an orange powder was obtained ( $\mathrm{m}=420 \mathrm{mg}$, $57.5 \%$ ). Anal. Calc. for $\mathrm{C}_{46} \mathrm{H}_{50} \mathrm{OSmBN}_{2}$ : C 68.53; H 5.57; N 3.80; Found C 67.45; H 6.15; N 4.12. ${ }^{1} \mathrm{H}$ NMR $\left(\mathrm{C}_{6} \mathrm{D}_{6}\right): 10.12$ (s, $1 \mathrm{H}, \mathrm{H}$ diimine), 9.28 (d, 2H, o'-Ph), 8.89 (d, 4H,o-Ph), $7.86\left(\mathrm{t}, 2 \mathrm{H}, m^{\prime}-\mathrm{Ph}\right), 7.72\left(\mathrm{t}, 1 \mathrm{H}, p^{\prime}-\mathrm{Ph}\right), 7.25(2 \mathrm{t}, 6 \mathrm{H}, m, p-\mathrm{Ph}), 5.29(\mathrm{~s}, 2 \mathrm{H}$, 
HCp), 3.28 (d, 4H, p-tol), 3.15 (s, 3H, Me(p-tol), 0.099 (s, 6H, N-Me), -1.45 (m, 4H, $\mathrm{Me}\left(p\right.$-tol), $-6.2\left(\mathrm{~m}, 4 \mathrm{H}, \mathrm{BH}_{4}\right)$.

\subsection{In situ preparations of 4', 5', 6'}

The procedure was different for these compounds, they were not isolated but prepared in situ by mixing the reactants, and the resulting solution was used as it was for subsequent polymerisation experiments: starting materials (1b, $10.3 \mathrm{mg}, 2510^{-3} \mathrm{mmol}+$ $\mathrm{KCp}^{4 \mathrm{i}}, 13.4 \mathrm{mg}, 5010^{-3} \mathrm{mmol} ; \mathbf{2 a}, 10.5 \mathrm{mg}, 2210^{-3} \mathrm{mmol}+\mathrm{KCp}^{*}, 5.3 \mathrm{mg}, 2610^{-3}$ mmol; 3, $13.7 \mathrm{mg}, 2210^{-3} \mathrm{mmol}+\mathrm{KCp}^{\mathrm{Ph} 3}, 8.4 \mathrm{mg}, 2510^{-3} \mathrm{mmol}$, respectively) were charged in a vessel containing the required solvent (THF or toluene, $5 \mathrm{~mL}$ ). The mixture was stirred at room temperature for several hours. $5 \mathrm{~mL}$ of solvent were added just before polymerisation. Considering that the expected compound was quantitatively formed in the case of 4' and 6' ( ${ }^{1} \mathrm{H}$ NMR check, by comparison with spectral data of the known products $\mathbf{4}$ and $\mathbf{6}$ ), the method, which had also proved efficient for the synthesis of $\mathrm{Cp}^{*}{ }_{2} \mathrm{Sm}\left(\mathrm{BH}_{4}\right)(\mathrm{THF}),{ }^{49}$ was adopted for $\mathbf{5}$ ' as well.

\subsection{Polymerisation of MMA}

In a glove box, to a solution containing the pre-catalyst $\left(2.5 \times 10^{-5} \mathrm{~mol}\right)$ dissolved in 10 $\mathrm{mL}$ of solvent or the in situ freshly prepared pre-catalyst (see above), was added the required amount of co-catalyst at room temperature. The vessel was sealed with a glass stopper and a rubber septum. After stirring for $5 \mathrm{~min}$, the vessel was transferred on a Schlenk line at the desired temperature. The polymerisation was started by direct addition of monomer to the catalyst solution by means of a syringe. The mixture was then allowed to stir for a given time or until the viscosity of the medium had stopped the 
magnetic barrel. The experiment was ended up by opening the vessel in air and the successive addition of standard water-containing solvent. The solution was poured in ethanol with vigorous stirring, leading to the precipitation of the polymer, which was filtrated and dried $24 \mathrm{~h}$ under vacuum at room temperature.

\subsection{Characterisation of PMMA}

${ }^{1} \mathrm{H}$ NMR was recorded on Bruker $\mathrm{AC} 300$ using $\mathrm{CDCl}_{3}$ as solvent at $300 \mathrm{~K}$. Chemical shifts were referenced to residual $\mathrm{CHCl}_{3}$ in the solvent $(\delta=7.26 \mathrm{ppm})$. Molecular weights were determined by size exclusion chromatography on a Gynkotek P580A apparatus equipped with two Jordi Gel DVB mixed B columns and an IOTA 2 refractive index detector. Polymer samples were dissolved in THF $\left(10 \mathrm{mg} \cdot \mathrm{mL}^{-1}\right)$ and elution was performed at $1 \mathrm{~mL} \cdot \mathrm{min}^{-1}$ in $\mathrm{THF}$ at $20{ }^{\circ} \mathrm{C}$. Number-average molecular weights $\left(\bar{M}_{n}\right)$ and polydispersity indices $\left(\bar{M}_{w} \bar{M}_{n}\right)$ of PMMA are given with respect to polystyrene standards. Differential Scanning Calorimetry (DSC) measurements were performed on a TA Instruments 2920 DSC. Samples of c.a. $10 \mathrm{mg}$ were scanned under nitrogen flow $\left(60 \mathrm{~mL} \cdot \mathrm{min}^{-1}\right.$; ramp rate $\left.10{ }^{\circ} \mathrm{C} \cdot \mathrm{min}^{-1}\right)$. Glass transition temperatures were determined on the second scan to ensure identical thermal histories.

\section{Conclusion}

This paper presents an extensive study of the use of borohydrido complexes of lanthanides for MMA polymerisation for the first time. Such complexes allow formation of highly syndiotactic or isotactic material, depending on the nature of 
ancillary ligands, the polarity of the reaction medium and the presence -or not- of an alkylating agent as co-catalyst.

$\mathrm{Nd}\left(\mathrm{BH}_{4}\right)_{3}(\mathrm{THF})_{3}$ affords highly syndiotactic PMMA, but it is really active only in the presence of an alkylating reagent. Complementary experiments undertaken with divalent samarocenes show that the samarium initiator bearing two bulky $\mathrm{Cp}^{*}$ ' ligands is one of the best catalysts of syndiospecific polymerisation of MMA yet described: a $88 \%$ syndiotactic PMMA is obtained at $0{ }^{\circ} \mathrm{C}$.

\section{Acknowledgments}

The authors whish to thank M. Antunes (Socrates fellow) for preliminary organometallic syntheses, Dr. A. Hafid and F. Moingeon for preliminary polymerisation experiments, and Dr C. H. Brachais for SEC facilities.

\section{References}

1. Inanaga J, Furuno H, Hayano T Chem. Rev. 2002; 102: 2211.

2. Gromada J, Carpentier JF, Mortreux A Coord. Chem. Rev. 2004; 248: 397-410.

3. Yasuda H J. Organomet. Chem. 2002; 647: 128.

4. Evans WJ, Ulibarri TA, Ziller JW Organometallics 1991; 10: 134.

5. Jeske G, Lauke H, Mauermann H, Swepston PN, Schumann H, Marks TJ J. Am. Chem. Soc. 1985; 107: 8091.

6. Olonde X, Mortreux A, Petit F J. Mol. Catal. 1993; 82: 75. 
7. Baudry D, Dormond A, Lachot B, Zucchi G, Visseaux M J. Organomet. Chem. 1997; 547: 157.

8. $\quad$ Ephritikhine M Chem. Rev. 1997; 97: 2193.

9. Guillaume SM, Schappacher M, Soum A Macromolecules 2003; 36: 54.

10. Bonnet F, Visseaux M, Pereira A, Barbier-Baudry D Macromolecules 2005; 38: 3162.

11. Visseaux M, Chenal T, Mortreux A, Roussel P J. Organomet. Chem. 2005; in press.

12. Hatada K, Kitayama T Polym. Int. 2000; 49: 11.

13. Zundel T, Teyssie P, Jerome R Polymer 2002; 43: 7191.

14. Yasuda H, Yamamoto H, Yokota K, Miyake S, Nakamura A J. Am. Chem. Soc. 1992; 114: 4908.

15. Boffa LS, Novak BM Macromolecules 1994; 27: 6993.

16. Giardello MA, Yamamoto Y, Brard L, Marks TJ J. Am. Chem. Soc. 1995; 117: 3276.

17. Liu JF, Shen ZQ, Sun JQ Eur. Pol. J. 1996; 32: 883.

18. Mao L, Shen Q J. Pol. Sci., Part A: Pol. Chem. 1998; 36: 1593.

19. Yasuda H, Yamamoto H, Takemoto Y, Yamashita M, Yokota K, Miyake S, Nakamura A Makromol. Chem., Macromol. Symp. 1993; 67: 187.

20. Dove AP, Gibson VC, Marshall EL, White AJP, Williams DJ Chem. Commun. $2002 ; 1208$.

21. Rodriguez-Delgado A, Mariott WR, Chen EYX Macromolecules 2004; 37: 3092. 
22. Nakayama Y, Shibahara T, Fukumoto H, Nakamura A, Mashima K Macromolecules 1996; 29: 8014.

23. Knjazhanski SY, Elizalde L, Cadenas G, Bulychev BM J. Organomet. Chem. 1998; 568: 33 .

24. Yasuda H, Yamamoto H, Yamashita M, Yokota K, Nakamura A, Miyake S, Kai Y, Kanehisa N Macromolecules 1993; 26: 7134.

25. Matsumoto A, Mohri Y J. Pol. Sci., Part A: Pol. Chem. 1999; 37: 2803.

26. Isobe Y, Yamada K, Nakano T, Okamoto Y J. Pol. Sci., Part A: Pol. Chem. 2000; 38: 4693.

27. Nugay T, Hamoudi ZT Polym. Prepr. 2001; 42: 421.

28. Wang JS, Jerome R, Teyssie P Macromolecules 1994; 27: 4902.

29. Kawagushi S, Nomura E, Ito K Polym. J. 1998; 30: 546.

30. Han YK, Park JM, Choi SK J. Polym. Sci. 1982; 20: 1549.

31. Bonnet F, Visseaux M, Pereira A, Barbier-Baudry D Macromol. Rapid Commun. 2004; 25: 873-877.

32. Kabir SMH, Rahman MT J. Organomet. Chem. 2001; 619: 31.

33. Ihara E, Morimoto M, Yasuda H Macromolecules 1995; 28: 7886.

34. Zhou SL, Wang SW, Yang GS, Liu XY, Sheng EH, Zhang KH, Cheng L, Huang ZX Polyhedron 2003; 22: 1019.

35. Nodono M, Tokimitsu T, Makino T Macromol. Chem. Phys. 2003; 204: 877.

36. Bonnet F, Visseaux M, Hafid A, Barbier-Baudry D, Vigier E, Kubicki MM Inorg. Chem. 2004; 43: 3682-3690.

37. Anwander R, Klimpel MG, Dietrich HM, Shorokhov DM, Scherer W J. Chem. Soc. Chem. Commun. 2003; 1008. 
38. Bourget-Merle L, Lappert MF, Severn JR Chem. Rev. 2002; 102: 3031.

39. Hatada K J. Pol. Sci. Part A: Pol. Chem. 1999; 37: 245.

40. Bonnet F, Visseaux M, Barbier-Baudry D J. Organomet. Chem. 2004; 689: 264269.

41. Visseaux M, Barbier-Baudry D, Blacque O, Hafid A, Richard P, Weber F New J. Chem. 2000; 24: 939.

42. Shen Q, Yao Y J. Organomet. Chem 2002; 647: 180.

43. Hirsch SS, Bailey WJ J. Org. Chem. 1978; 43: 4090.

44. Bonnet F, Visseaux M, Barbier-Baudry D, Vigier E, Kubicki MM Chem. Eur. J. 2004; 10: 2428-2434.

45. Mirsaidov U, Shaimuradov IB, Khikmatov M Russ. J. Inorg. Chem. 1986; 5: 753.

46. Barbier-Baudry D, Blacque O, Hafid A, Nyassi A, Sitzmann H, Visseaux M Eur. J. Inorg. Chem. 2000; 2333.

47. Arndt S, Okuda J Chem. Rev. 2002; 102: 1953 and refs therein.

48. Yao Y, Xue M, Luo Y, Zhang Z, Jiao R, Zhang Y, Shen Q, Wong W, Yu K, Sun J J. Organomet. Chem. 2003; 678: 108.

49. Anal. Calc. for $\mathrm{C}_{46} \mathrm{H}_{50} \mathrm{OSmBN}_{2}$ : C 68.53; H 5.57; N 3.80; Found C 67.45; H 6.15; $\mathrm{N} 4.12 .$, to be published elsewhere. 


\section{Table 1}

Results of MMA polymerisation using $\mathrm{Nd}\left(\mathrm{BH}_{4}\right)_{3}(\mathrm{THF})_{3}(\mathbf{1 a})$ as pre-catalyst ${ }^{a}$

run co-catalyst $^{b}$ solvent time Yield $10^{-3} \times \bar{M}_{n}{ }^{c}$ PDI $^{d}$ Triad fractions
(h) $(\%)$

$(\%)$

\begin{tabular}{|c|c|c|c|c|c|c|c|c|c|}
\hline & & & & & & & \multirow{2}{*}{$\mathrm{mm}$} & \multirow[b]{2}{*}{$\mathrm{mr}$} & \multirow[b]{2}{*}{$\mathrm{rr}$} \\
\hline & & & & & & & & & \\
\hline $1^{e}$ & - & tol & 3 & 10 & 35.4 & 1.8 & 0.4 & 18.2 & 81.4 \\
\hline $2^{e}$ & $\mathrm{Mg}^{\mathrm{n}} \mathrm{Bu}_{2}$ & tol & 3 & 20 & 7.4 & 1.8 & 38.2 & 19.4 & 42.4 \\
\hline $3^{e}$ & BuLi & tol & 3 & 95 & $41^{g}$ & 1.9 & 92.7 & 6.3 & 1.0 \\
\hline 4 & BuLi & tol & 23 & 92 & $34^{g}$ & - & 93 & 6.2 & 0.8 \\
\hline $5^{f}$ & $\mathrm{BuLi}$ & Tol & 65 & 27 & 85 & 4.7 & 85.4 & 10.0 & 4.6 \\
\hline 6 & $\mathrm{Mg}^{\mathrm{n}} \mathrm{Bu}_{2}$ & THF & 6 & 78 & $45^{g}$ & - & 5.7 & 23.8 & 70.5 \\
\hline 7 & $\mathrm{BuLi}$ & THF & 23 & 81 & 110 & 2.1 & 2.7 & 21.8 & 75.5 \\
\hline $8^{f}$ & $\mathrm{BuLi}$ & THF & 65 & 6.7 & $-{ }^{h}$ & - & 3.1 & 22.3 & 74.6 \\
\hline
\end{tabular}

${ }^{a} \mathrm{~T}=-40{ }^{\circ} \mathrm{C},[\mathrm{Nd}]=2.510^{-3} \mathrm{M},[\mathrm{MMA}] /[\mathrm{Nd}]=500 .{ }^{b} \mathrm{Mg}^{\mathrm{n}} \mathrm{Bu}_{2}: 3$ equivalents per $\mathrm{Nd}$; BuLi: 4 equivalents per $\mathrm{Nd} .{ }^{c}$ Determined by SEC against PS standards. ${ }^{d}$ PDI $=$ $\bar{M}_{w} \bar{M}_{n} .{ }^{e}$ in the presence of $\left(2,6-{ }^{\mathrm{t}} \mathrm{Bu}-4-\mathrm{Me}-\mathrm{C}_{6} \mathrm{H}_{3} \mathrm{O}\right){ }_{2} \mathrm{AlEt}$ (1 equiv. per $\left.\mathrm{Nd}\right) ; \mathrm{T}=0{ }^{\circ} \mathrm{C} .{ }^{f}$ in absence of organometallic pre-catalyst. ${ }^{g}$ presence of a shoulder at high molecular weights. ${ }^{h}$ undetermined. 


\section{Table 2}

Results of MMA polymerization using monosubstituted organolanthanide precatalysts

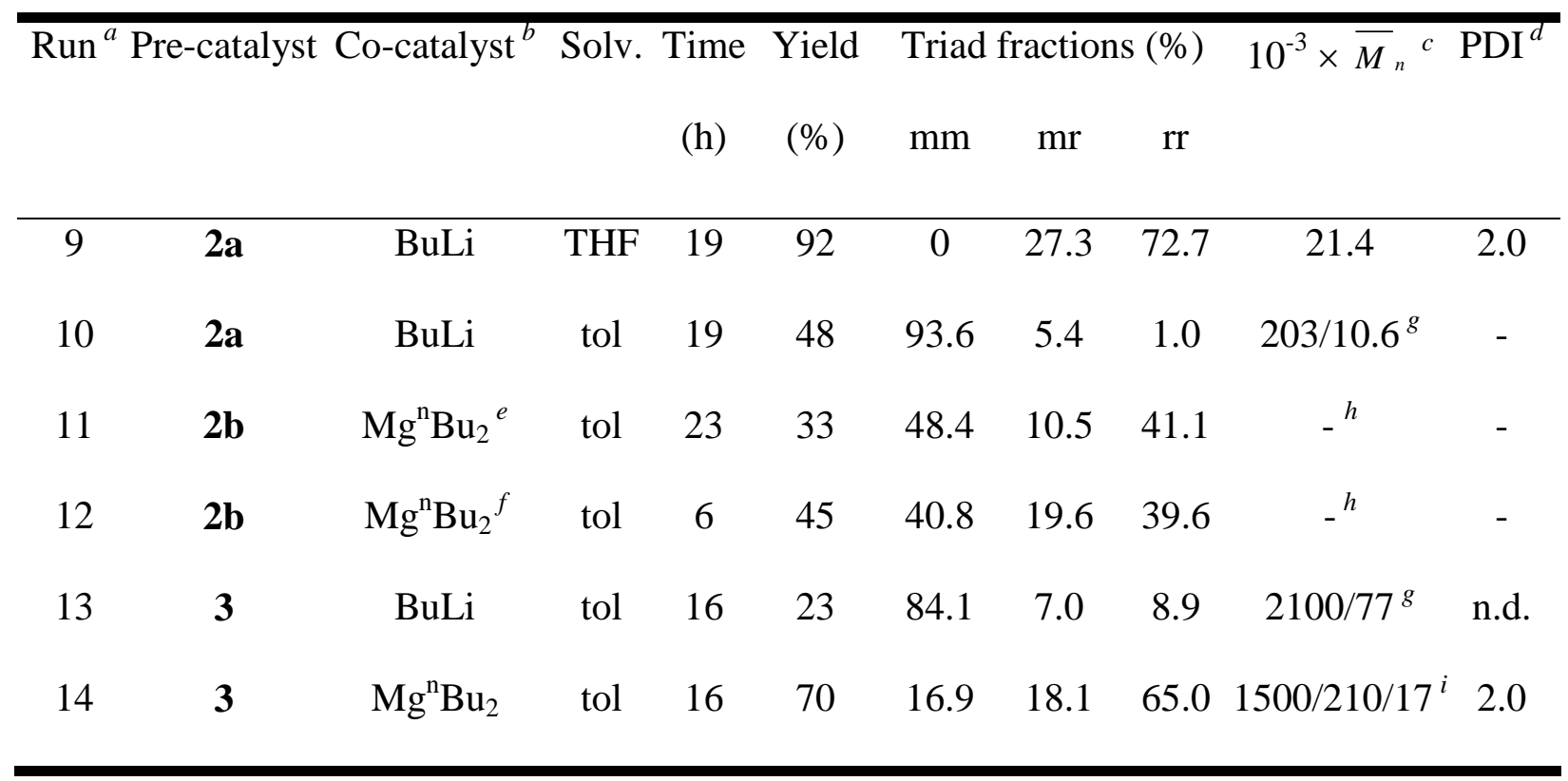

${ }^{a} \mathrm{~T}=0{ }^{\circ} \mathrm{C},[\mathrm{Ln}]=2.510^{-3} \mathrm{M},[\mathrm{MMA}] /[\mathrm{Ln}]=500 .{ }^{b} \mathrm{Mg}^{\mathrm{n}} \mathrm{Bu}_{2}: 2$ equivalents per $\mathrm{Ln}$;

BuLi: 3 equivalents per Ln. ${ }^{c}$ Measured by SEC against PS standards. ${ }^{d}$ PDI $=\bar{M}_{w}{ }_{M_{n}}$.

${ }^{e} 1$ equivalent per Nd. ${ }^{f} 10$ equivalents per Nd. ${ }^{g}$ bimodal. ${ }^{h}$ undetermined. ${ }^{i}$ multimodal. 
Table 3

Results of MMA polymerisation using disubstitued organolanthanide catalysts

\begin{tabular}{|c|c|c|c|c|c|c|c|c|c|c|}
\hline \multicolumn{3}{|c|}{$\operatorname{Run}^{a}$ Pre-catalystCo-catalyst } & \multirow[t]{2}{*}{ Solv. } & \multirow{2}{*}{$\begin{array}{l}\text { Time } \\
\text { (h) }\end{array}$} & \multirow{2}{*}{$\begin{array}{l}\text { Yield } \\
(\%)\end{array}$} & \multicolumn{3}{|c|}{ Triad fractions $(\%)$} & \multirow[t]{2}{*}{$10^{-3} \times \bar{M}_{n}$} & \multirow[t]{2}{*}{$\mathrm{PDI}^{a}$} \\
\hline & & & & & & $\mathrm{mm}$ & $\mathrm{mr}$ & $\mathrm{rr}$ & & \\
\hline $15^{e}$ & 4 & - & tol & 4 & 100 & - & - & 68.0 & 540 & 1.45 \\
\hline $16^{f}$ & 4 & $\mathrm{BuLi}$ & tol & 22 & 38 & 92.3 & 6.3 & 1.4 & $337 / 16^{g}$ & - \\
\hline 17 & 4 ' & $\mathrm{BuLi}$ & tol & 20 & 33 & 85.2 & 11.0 & 3.8 & $506 / 15^{g}$ & \\
\hline 18 & 4 ' & $\mathrm{Mg}^{\mathrm{n}} \mathrm{Bu}_{2}$ & tol & 20 & 45 & 40.7 & 20.3 & 39.0 & $12.5^{h}$ & - \\
\hline 19 & 5 , & $\mathrm{BuLi}$ & THF & 21 & 89 & 0 & 27.7 & 72.3 & 31 & 2.1 \\
\hline 20 & 5 , & $\mathrm{Mg}^{\mathrm{n}} \mathrm{Bu}_{2}$ & THF & 21 & 33 & 3.6 & 18.1 & 78.3 & 30.5 & 3.6 \\
\hline 21 & 5 ' & $\mathrm{BuLi}$ & tol & 15 & 57 & 76.9 & 11.3 & 11.8 & $23^{h}$ & - \\
\hline 22 & 5 ' & $\mathrm{Mg}^{\mathrm{n}} \mathrm{Bu}_{2}$ & tol & 15 & 100 & 23.5 & 8.5 & 68.0 & insoluble & \\
\hline 23 & 6 ' & - & tol & 16 & 90 & 0 & 18.2 & 81.8 & 418 & 2.5 \\
\hline 24 & 6 & $\mathrm{BuLi}$ & THF & 23 & 67 & 2.2 & 28.4 & 69.4 & 31.5 & 2.1 \\
\hline 25 & $7 a$ & BuLi & Tol & 16 & 100 & 95.6 & 3.1 & 1.3 & 1000 & 1.5 \\
\hline 26 & $7 b$ & $\mathrm{BuLi}$ & Tol & 16 & 59 & 91.8 & 6.7 & 1.5 & $700 / 24^{g}$ & - \\
\hline $27^{\mathrm{f}}$ & 8 & $\mathrm{BuLi}$ & THF & 24 & 79 & 0.5 & 24.3 & 75.2 & 36.4 & 2.4 \\
\hline $28^{\mathrm{f}}$ & 8 & $\mathrm{BuLi}$ & tol & 3 & 68 & 93.4 & 5.0 & 1.6 & 700 & br. \\
\hline
\end{tabular}

${ }^{a} \mathrm{~T}=0{ }^{\circ} \mathrm{C},[\mathrm{Ln}]=2.510^{-3} \mathrm{M},[\mathrm{MMA}] /[\mathrm{Ln}]=500 .{ }^{b} \mathrm{Mg}^{\mathrm{n}} \mathrm{Bu}_{2}: 1$ equivalent per $\mathrm{Ln} ; \mathrm{BuLi}:$ 2 equivalents per Ln. ${ }^{c}$ Measured by SEC against PS standards. ${ }^{d} \mathrm{PDI}=\bar{M}_{w} \bar{M}_{n}{ }^{e} \mathrm{~T}=$ $25{ }^{\circ} \mathrm{C},[\mathrm{MMA}] /[\mathrm{Sm}]=50, \mathrm{v}_{\text {(toluene) }}=1.4 \mathrm{~mL} .{ }^{f} \mathrm{~T}=-10{ }^{\circ} \mathrm{C} .{ }^{g}$ bimodal. ${ }^{h}$ presence of a shoulder at high molecular weights. 
Table 4

Results of MMA polymerization using divalent samarocenes catalysts

\begin{tabular}{|c|c|c|c|c|c|c|c|}
\hline \multirow[t]{2}{*}{$\operatorname{run}^{a}$} & \multirow[t]{2}{*}{ Initiator } & \multirow{2}{*}{$\begin{array}{l}\text { Yield } \\
(\%)\end{array}$} & \multicolumn{3}{|c|}{ Triad fractions (\%) } & \multirow[t]{2}{*}{$10^{-3} \times \bar{M}_{n}^{b}$} & \multirow[t]{2}{*}{$\mathrm{PDI}^{\mathrm{C}}$} \\
\hline & & & $\mathrm{mm}$ & $\mathrm{mr}$ & $\mathrm{rr}$ & & \\
\hline 29 & 9 & 9 & 14.0 & 17.6 & 68.4 & 24 & 6.1 \\
\hline 30 & 10 & 37 & 0 & 12.0 & 88.0 & 146 & 2.4 \\
\hline 31 & 11 & 99 & 0.7 & 21.2 & 78.1 & 274 & 1.5 \\
\hline
\end{tabular}

${ }^{a} \mathrm{~T}=0{ }^{\circ} \mathrm{C},[\mathrm{Sm}]=2.510^{-3} \mathrm{M},[\mathrm{MMA}] /[\mathrm{Sm}]=500$, co-catalyst: none, polymerization time: 24 h, solvent: toluene. ${ }^{b}$ Measured by SEC against PS standards. ${ }^{c}$ PDI $=\bar{M}_{w}{ }_{M_{n}}$ 


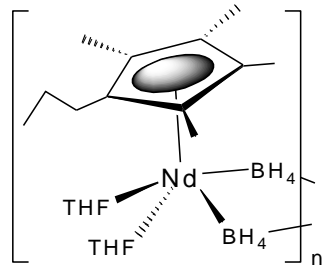

$2 a$
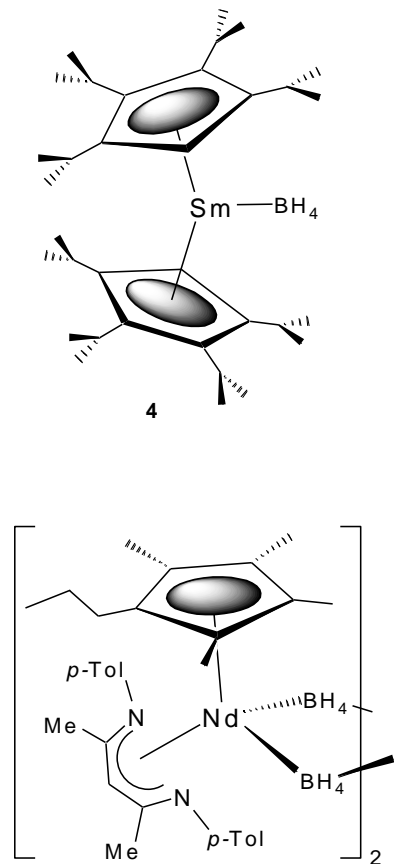

$7 a$

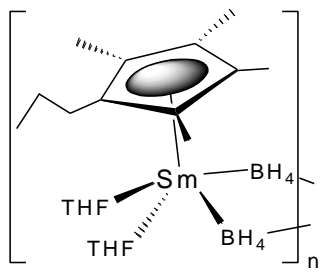

2b
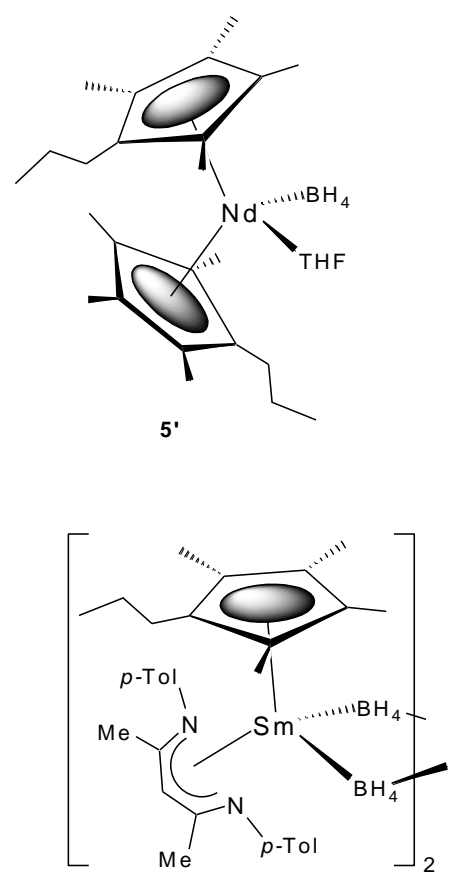

$7 b$
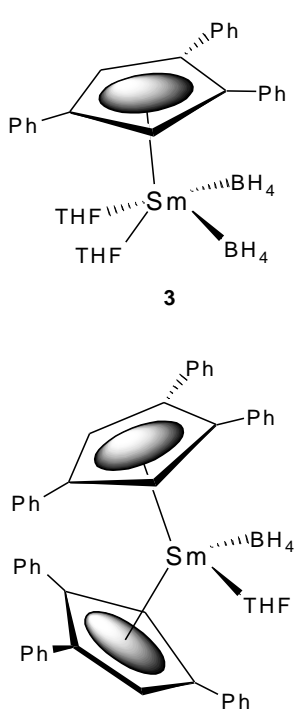

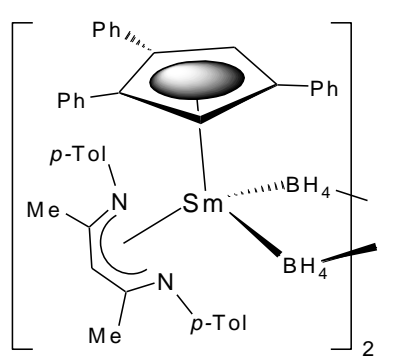

8

Chart 1. Lanthanide complexes used as pre-catalysts
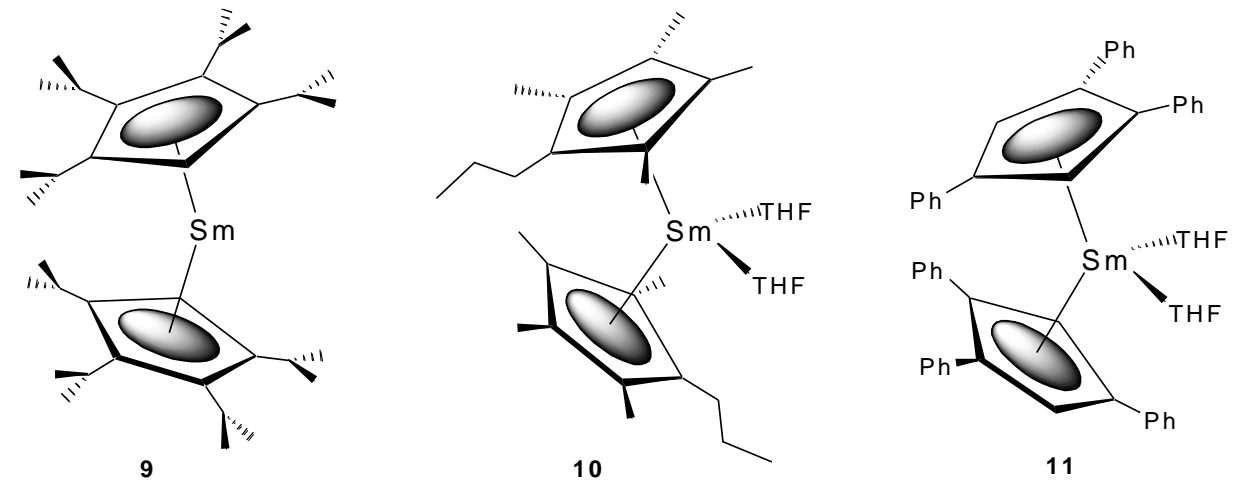

Chart 2. The samarocenes used as initiators for MMA polymerisation 